\title{
Correction to: Socioeconomic status in children is associated with spontaneous activity in right superior temporal gyrus
}

\author{
Claudinei Eduardo Biazoli Jr ${ }^{1}$ • Giovanni Abrahão Salum ${ }^{2,3} \cdot$ Ary Gadelha $^{3,4} \cdot$ Keila Rebello $^{1}$. \\ Luciana Monteiro Moura ${ }^{3,4}$. Pedro Mario Pan ${ }^{3,4}$. Elisa Brietzke ${ }^{3,4}$. Euripedes Constantino Miguel M $^{3,5}$ \\ Luis Augusto Rohde ${ }^{2,3}$ • Rodrigo Affonseca Bressan ${ }^{3,4}$ • Andrea Parolin Jackowski ${ }^{3,4}$ • João Ricardo Sato ${ }^{1,3}$
}

Published online: 29 May 2019

(C) Springer Science+Business Media, LLC, part of Springer Nature 2019

Correction to: Brain Imaging and Behavior https://doi.org/10.1007/s11682-019-00073-z

The original version of this article contained mistakes. The surname of Elisa Brietzke was misspelled as "Brietske".

The original article has been corrected.

Publisher's note Springer Nature remains neutral with regard to jurisdictional claims in published maps and institutional affiliations.

The online version of the original article can be found at https://doi.org/ 10.1007/s11682-019-00073-Z

João Ricardo Sato

joao.sato@ufabc.edu.br

1 Center of Mathematics, Computing and Cognition, Universidade Federal do ABC, Av. dos Estados, 5001. Bairro Bangu., Santo André, SP CEP 09210-580, Brazil

2 Hospital de Clinicas de Porto Alegre and Department of Psychiatry, Federal University of Rio Grande do Sul, Porto Alegre, Brazil

3 National Institute of Developmental Psychiatry for Children and Adolescents, CNPq, Sao Paulo, Brazil

4 Interdisciplinary Lab for Clinical Neurosciences (LiNC), Universidade Federal de Sao Paulo (UNIFESP), Sao Paulo, Brazil

5 Department of Psychiatry, School of Medicine, University of Sao Paulo, Sao Paulo, Brazil 